\title{
ANÁLISE SANITÁRIA DE SEMENTES DE TRIGO DURANTE O
} ARMAZENAMENTO

Vanessa Nogueira Soares ${ }^{1}$, Bruna Barreto dos Reis ${ }^{2 *}$, Andréia da Silva Almeida ${ }^{1}$, Anita de Farias Nunes ${ }^{3}$, Lilian Madruga Tunes ${ }^{4}$

1 Pós Doutoranda no programa de Ciência e Tecnologia de Sementes da Universidade Federal de Pelota- Pelotas-Brasil

2 Doutoranda no programa de Pós Graduação em Ciência e Tecnologia de Sementes*(brunabarretoreis-@hotmail.com) 3 Graduanda na Universidade Federal de Pelotas

4 Professora Doutora no programa de Pós Graduação em Ciência e Tecnologia de Sementes

Recebido em: 08/09/2015 - Aprovado em: 14/11/2015 - Publicado em: 01/12/2015 DOI: http://dx.doi.org/10.18677/Enciclopedia_Biosfera_2015_245

As sementes de trigo podem ser infestadas e/ou infectadas por microrganismos que podem causar a deterioração desta estrutura de propagação. Objetivou-se avaliar a qualidade sanitária de sementes de trigo durante seis meses de armazenamento. Foram utilizados cinco lotes de sementes de trigo (Triticum aestivum L.), cultivar TBIO Pioneiro sem tratamento. As sementes foram armazenadas por seis meses em câmara fria. Foi determinado o teor de água e realizados testes de germinação e incubação em substrato de papel em quatro épocas de armazenamento $(0,2,4$ e 6 meses). O delineamento experimental foi inteiramente casualizado, utilizando-se quatro repetições para cada lote. O lote 4 diferenciou-se dos demais no teor inicial de água e o percentual inicial de germinação. A viabilidade das sementes não foi afetada durante período avaliado. Foram detectados seis gêneros fúngicos nas sementes de trigo, são eles: Alternaria sp., Bipolaris sp., Fusarium sp., Aspergillus sp,. Penicillium sp. e Rhizopus sp. Os fungos Alternaria sp., Bipolaris e Fusarium sp., perdem viabilidade durante o armazenamento enquanto Aspergillus sp. e Pencillium sp. apresentam maior percentual de incidência ao longo do período de armazenamento.

PALAVRAS-CHAVE: patógenos, sanidade de sementes, Triticum aestivum L.,

\section{HEALTH ANALYSIS OF SEEDS OF WHEAT DURING STORAGE}

\begin{abstract}
Wheat seeds may be contaminated and / or infected by microorganisms that can cause seed deterioration. The aim of this study was to evaluate the health quality of wheat seeds during six months of storage. Five lots of wheat (Triticum aestivum L.) seeds untreated of $\mathrm{cV}$. TBIO Pioneiro were used. The seeds were stored for six months in cold chamber. It was determined the seed moisture content and conducted standard germination test and blotter test into four periods of storage $(0,2,4$ and 6 months). The experimental design was completely randomized, using four
\end{abstract}


replications for each lot. Lot 4 differed from the others in the initial seed moisture content initial germination percentage. The seeds viability was not affected in the storage period. Were detected the following genera of fungi in the seeds by the health test: Alternaria, Bipolaris, Fusarium, Aspergillus, Penicillium, Rhizopus. The fungus Alternaria sp., Bipolaris and Fusarium sp., lost viability during storage while Aspergillus sp. and Pencillium sp they had higher incidence rate during the storage period.

KEYWORDS: pathogens, seed health, Triticum aestivum L.,

\section{INTRODUÇÃO}

Alimentos ricos em carboidratos, tais como massas, pães e biscoitos são a base da alimentação humana. A farinha de trigo (Triticum aestivum L.) é um dos principais ingredientes desses produtos. A produção brasileira desse cereal, estimada em 7 milhões de toneladas para safra 2015 (CONAB, 2015) não é suficiente para atender a sua demanda, por isso o aumento do total de trigo produzido no país, torna-se necessário (EMBRAPA, 2015).

Para atender a demanda de alimentos e melhorar o rendimento dos cultivos no campo, é necessário que se tenha sementes de qualidade. A qualidade de sementes é um fator imprescindível para que se possa garantir uma produção satisfatória sem perdas no estabelecimento das lavouras. Trata-se de um fator fundamental para o sucesso dos cultivos agrícolas, afetando o rendimento e a qualidade do produto final (BOLIGON et al., 2011). Essa característica é resultante do somatório dos atributos genéticos, físicos, fisiológicos e sanitários que afetam a sua capacidade de originar plantas de alta produtividade (PESKE, 2012).

Segundo OHLSON et al. (2010), as sementes de trigo têm apresentado sérios problemas quanto à qualidade, fato decorrente da ocorrência de chuvas no período de pré-colheita e de danos mecânicos resultantes da colheita, secagem e armazenamento. Como o armazenamento ocorre durante o verão, as sementes são mais suscetíveis a oscilações de temperatura, umidade relativa do ar e pragas de armazenamento. Logo, a produção pode ser prejudicada pela deterioração das sementes de trigo durante o armazenamento.

A presença de patógenos nas sementes, independentemente de sua transmissibilidade, pode afetar o vigor e o rendimento em campo (MACHADO, 2010). Elevadas porcentagens de sementes infeccionadas estão associadas ao decréscimo no poder germinativo e ao menor crescimento da plântula no início do desenvolvimento.

O processo de deterioração causado por fungos pode ter início no campo, durante o processo de maturação e se estender até ao armazenamento. Porém, os fungos dos gêneros Aspergillus e Penicillium ocorrem com frequência em sementes recém-colhidas e apesar das baixas percentagens de ocorrência, sobrevivem e proliferam-se em ambientes com baixa umidade. Há assim a deterioração de sementes devido a destruição do embrião levando ao decréscimo de viabilidade e perda do valor comercial das sementes (CARVALHO e NAKAGAWA, 2012).

Desta forma, objetivou-se avaliar a qualidade sanitária de sementes de trigo durante o armazenamento. 


\section{MATERIAL E MÉTODOS}

Foram utilizados cinco lotes de sementes comerciais de trigo (Triticum aestivum L.), não tratadas, cultivar TBIO Pioneiro, produzidas na região Noroeste do Estado do Rio Grande do Sul. Primeiramente foi realizada uma caracterização inicial dos lotes de sementes de trigo, com determinação do grau de umidade, percentual de germinação e avaliação da qualidade sanitária pelo teste de incubação em substrato de papel.

Determinação do grau de umidade: efetuada pelo método estufa a $105{ }^{\circ} \mathrm{C} \pm 3 \stackrel{\circ}{\circ} \mathrm{C}$, durante 24 horas, utilizando-se duas subamostras de $4,5 \mathrm{~g}$ de sementes para cada lote, seguindo as especificações das Regras para Análise de Sementes (BRASIL, 2009). Os resultados foram expressos em porcentagem para cada lote.

Germinação: conduzido a $20^{\circ} \mathrm{C}$, com 200 sementes por repetição de cada lote (quatro subamostras de 50 sementes), em rolos de papel germitest, os quais foram umedecidos com água equivalente a 2,5 vezes a massa do substrato seco. As avaliações foram realizadas aos quatro e aos oito dias após a semeadura e os resultados expressos em porcentagem de plântulas normais, anormais e sementes mortas (BRASIL, 2009).

Incubação em substrato de papel: foi realizado o exame das sementes após a incubação. Foram utilizadas oito subamostras de 25 sementes, colocadas em caixa tipo gerbox contendo papel filtro umedecido com água destilada. As caixas contendo as sementes foram levadas para a câmara de incubação a $20 \pm 2{ }^{\circ} \mathrm{C}$ por sete dias em regime intermitente de $12 \mathrm{~h}$ de luz/12h de escuro. A avaliação foi realizada sob microscópio estereoscópico, observando-se as estruturas dos patógenos, e quando necessário foi utilizado também o microscópio biológico para identificação mais segura dos patógenos associados (BRASIL, 2009).

Armazenamento: as sementes foram armazenadas em câmara fria $\left(16{ }^{\circ} \mathrm{C} ; 60 \%\right)$ durante o período de seis meses.

A determinação do grau de umidade, os testes de germinação e incubação em substrato de papel foram realizados a cada 2 meses durante o armazenamento, além da caracterização inicial. $O$ delineamento experimental foi inteiramente casualizado, utilizando-se quatro repetições para cada lote. Os tratamentos foram arranjados em esquema fatorial $5 \times 4$, sendo cinco lotes e quatro períodos de armazenamento. A significância do efeito dos tratamentos foi determinada pelo Teste F, sendo as médias do fator "lotes" comparadas pelo Teste de Tukey. Para o fator "período de armazenamento" foram ajustadas regressões polinomiais.

\section{RESULTADOS E DISCUSSÃO}

Não houve interação entre lotes e períodos de armazenamento para a variável germinação (Tabela 1). Todavia, para a incidência de fungos foi constada interação entre os fatores "lotes" e "períodos" (Tabela 1). 
TABELA 1. Médias e valores de $F$ para germinação (G), Alternaria (Alt), Aspergillus (Asp), Fusarium (Fus), Penicillium (Pen), Bipolaris (Bip) e Rhizopus (Rhi).

\begin{tabular}{|c|c|c|c|c|c|c|c|}
\hline Lote (L) & G & ALT & ASP & FUS & PEN & BIP & RHI \\
\hline 1 & 79 & 5 & 14,19 & 0,19 & 2,75 & 0,75 & 0,13 \\
\hline 2 & 78 & 3,94 & 11,81 & 0,13 & 2 & 0,25 & 0,38 \\
\hline 3 & 79 & 3,44 & 8,25 & 0 & 4,19 & 0,56 & 0,31 \\
\hline 4 & 93 & 29,44 & 3,81 & 0,38 & 0,88 & 1,13 & 0,06 \\
\hline 5 & 80 & 1,38 & 6,06 & 0 & 5,69 & 0,56 & 0,44 \\
\hline Teste F & $43,72^{\star \star}$ & $171,67^{\star *}$ & $35,42^{\star \star}$ & $3^{* *}$ & $3,09^{\star \star}$ & $3,13^{\star \star}$ & $2,45^{\mathrm{ns}}$ \\
\hline \multicolumn{8}{|l|}{$\begin{array}{l}\text { Períodos } \\
(\mathrm{P})\end{array}$} \\
\hline 0 & 84 & 0,75 & 0 & 0,3 & 0,5 & 1 & 0,35 \\
\hline 2 & 82 & 11,65 & 2,65 & 0,2 & 7,8 & 1,3 & 0,1 \\
\hline 4 & 81 & 8,1 & 13,7 & 0,05 & 2,9 & 0,3 & 0,5 \\
\hline 6 & 80 & 4,05 & 18,9 & $\begin{array}{l}-1,53^{-} \\
16\end{array}$ & 1,2 & 0 & 0,1 \\
\hline Teste $\mathrm{F}$ & $4,63^{* *}$ & $18,22^{* *}$ & $200,54^{\star *}$ & $2,93^{\star *}$ & $11,83^{* *}$ & $13,84^{\star *}$ & $4,56^{\star \star}$ \\
\hline Regressão & - & linear & linear & linear & quadrática & linear & cúbica \\
\hline $\begin{array}{l}\text { Valor } \\
\text { de p da } \\
\text { regressão }\end{array}$ & - & $1,108^{-8}$ & $2,285^{-32}$ & 0,0049 & $1,547^{-5}$ & $7,638^{-7}$ & 0,0009 \\
\hline $\begin{array}{l}\text { Interação } \\
L \times \text { P }\end{array}$ & $0,79^{\mathrm{ns}}$ & $4,49^{* *}$ & $21,04^{\star \star}$ & $1,97^{\star \star}$ & $6,63^{\star *}$ & $2,27^{\star \star}$ & $2,55^{\star \star}$ \\
\hline
\end{tabular}

** significativo ao nível de $5 \%$.

ns- não significativo

Conforme a caracterização inicial dos lotes demonstrada na Tabela 2, os lotes apresentaram teores de água iniciais semelhantes e ao redor de $12,5 \%$, excetuando

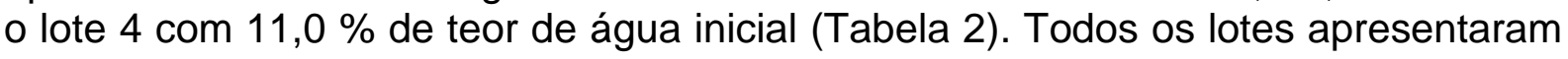
germinação dentro do padrão de comercialização que é de $80 \%$ para sementes de trigo (MAPA, 2013). De acordo com o resultado do teste de germinação, o lote 4 com $93 \%$ de germinação apresentou qualidade inicial superior aos demais lotes (Tabela 2). O lote $2 \mathrm{com} 84 \%$ de germinação não se diferenciou dos lotes 1 e $3 \mathrm{com}$ $81 \%$ e do lote $5 \mathrm{com} 80 \%$ de germinação (Tabela 2 ). 
TABELA 2. Teor de água (TA), germinação (G), de lotes de sementes de trigo antes do armazenamento.

\begin{tabular}{ccc}
\hline Lote & TA (\%) & $\mathrm{G} \mathrm{( \% )}$ \\
\hline 1 & 12,6 & $81 \mathrm{~b}$ \\
2 & 12,5 & $84 \mathrm{~b}$ \\
3 & 12,6 & $81 \mathrm{~b}$ \\
4 & 11,0 & $93 \mathrm{a}$ \\
5 & 12,5 & $80 \mathrm{~b}$ \\
\hline CV (\%) & - & 2,37 \\
\hline
\end{tabular}

Médias seguidas da mesma letra na coluna não diferem entre si pelo teste de Tukey $(p>0,05)$

Na Figura 1 é possível verificar a tendência de incidência inicial e durante o armazenamento de fungos nas sementes de trigo. $\mathrm{Na}$ análise inicial foi constatada a presença de Alternaria sp., Bipolaris sp., Fusarium sp., Aspergillus sp., Penicillium sp. e Rhizopus sp. Dentre esses, destaca-se a presença de Bipolaris e Fusarium que podem estar associados à doenças como a fusariose (Fusarium graminearum Schwabe) e a mancha foliar ou helmintosporiose [Bipolaris sorokiniana (Sacc.) Shoemaker], doenças que podem causar sérios danos a cultura do trigo, com perdas superiores a $10 \%$ para a fusariose e de cerca de $20 \%$ para a mancha foliar (BRANCÃO et al., 2008).

Aspergillus e Penicillium, por sua vez são fungos de armazenamento, que podem infectar as sementes logo após a colheita, porém em baixas taxas percentuais. No entanto, no decorrer do armazenamento eles sobrevivem e proliferam-se, pois necessitam de ambientes com menor umidade para se desenvolverem. Com o desenvolvimento, esses patógenos podem invadir o embrião das sementes, acentuando o processo de deterioração das sementes podendo culminar em perda do valor comercial de um lote pois esse processo pode levar a morte das sementes (CARVALHO \& NAKAGAWA, 2012). A presença de Rhizopus $\mathrm{sp}$. foi verificada nos lotes 2 e $3 \mathrm{com}$ incidência de $1 \%$ em todas as ocorrências (Figura 1F). 


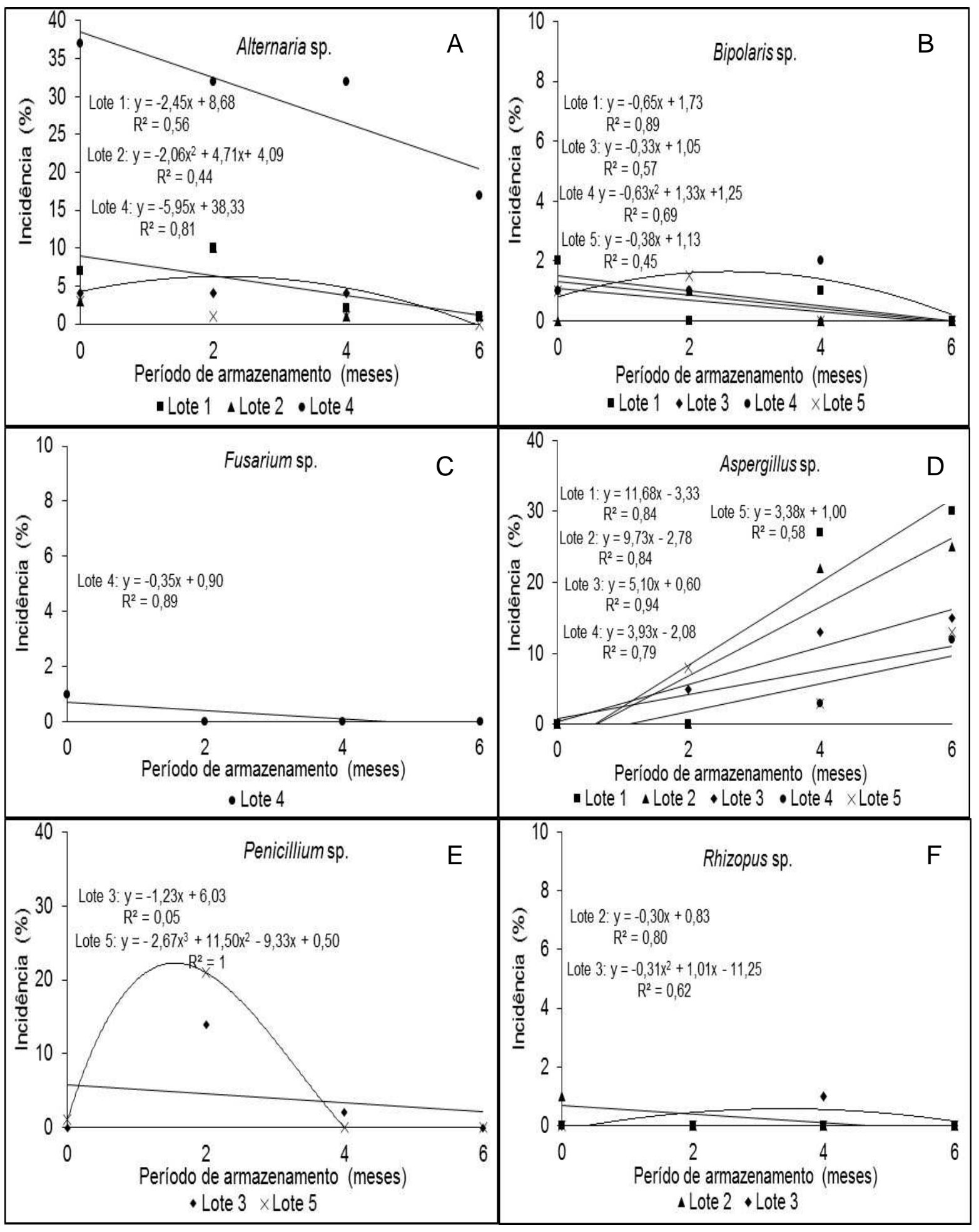

FIGURA 1 Incidência de Alternaria sp. (A); Bipolaris sp. (B); Fusarium sp. (C); Aspergillus sp. (D); Penicillium sp. (E) e Rhizopus sp. (F) em sementes de trigo armazenadas por seis meses. 
Todos os lotes apresentaram incidência de Alternaria sp. (Figura 1A), que variou de 3 a $37 \%$ de acordo com o lote, no entanto o lote 4 apresentou a maior taxa percentual de incidência desse gênero (37\%). Para os lotes 3 e 5 a interação entre lote e período não foi significativa. Segundo BRANCÃO et al. (2008) deve-se atentar para incidências elevadas de Alternaria sp., pois esse patógeno pode reduzir o estande inicial por ocasionar a morte de plântulas. No entanto, ao longo do armazenamento foi possível observara redução da incidência desse fungo.

A ocorrência de Bipolaris sp. foi baixa nas sementes, variando entre 0 e $2 \%$ (Figura 1B). Nos diferentes lotes, a partir do $2^{\circ}$ mês de armazenamento é possível verificar o seu declínio por ser um fungo de campo, não encontrando condições ideais para sobreviver em condições de armazenamento. Os lotes 1 e 4 apresentaram incidência inicial de $2 \%$, os lotes 3 e 5 de $1 \%$ e no lote 2 não houve incidência de Bipolaris sp. Entre o segundo e terceiro mês de armazenamento o percentual de Bipolaris sp. chegou a $0 \%$ em todos os lotes. Desta forma, é possível que o fungo tenha perdido viabilidade durante o armazenamento por necessitar de alta umidade para seu desenvolvimento.

Os lotes 2 e 5 não apresentaram incidência de Fusarium sp., provavelmente porquê esses lotes foram produzidos em áreas livres desse fungo, enquanto os lotes 1,3 e 4 apresentaram $1 \%$ de incidência, porém a partir do $2^{\circ}$ mês de armazenamento a sua incidência foi de $0 \%$ (Figura 1C). Por ter incidência inicial baixa e ser um fungo proveniente de campo a incidência desse patógeno chegou a $0 \%$ aos dois meses de armazenamento. Estes resultados são semelhantes aos apresentados por TELLES NETO et al. (2007) que relataram a queda na incidência do inóculo deste fungo de 100 a $0 \%$ em 11 meses de armazenamento.

A incidência de Aspergillus sp. aumentou durante o armazenamento (Figura 1D). O tempo de avaliação de seis meses de armazenamento não foi suficiente para perceber o momento em que a incidência de Aspergillus sp. começa a diminuir, o que foi observado por RUPOLLO et al. (2006) em aveia a partir dos seis meses de armazenamento. Contudo, avaliações posteriores a esse período de armazenamento se fazem necessárias para observar a tendência de comportamento desse gênero fúngico.

O fungo Penicillium sp. apresentou comportamento distinto dos demais fungos, com um percentual de incidência baixo no começo das avaliações e um pico que variou do $2^{\circ}$ ao $4^{\circ}$ mês entre os lotes, com posterior declínio (Figura 1E). É possível que a infecção de Penicillium sp. tenha ocorrido devido às condições geradas pela infecção de Aspergillus sp., uma vez que o primeiro apresentou contaminação oriunda do campo e 0 segundo foi detectado durante 0 armazenamento. De acordo com DHINGRA (2005), a ocorrência de espécies de Aspergillus sp. pode propiciar, por meio de água metabólica, o desenvolvimento de outros fungos que necessitam de um teor de umidade um pouco mais elevado, como as espécies de Penicillium sp.

De acordo com os dados apresentados na Tabela 3, é possível observar que a umidade das sementes variou pouco durante o período de armazenamento. A germinação dos lotes não diferiu dos dois aos seis meses de armazenamento. Isto é, a incidência de microrganismos nas sementes de trigo não afetou a viabilidade das sementes durante o período de armazenamento. No entanto, é importante destacar que a emergência de plântulas a campo e o vigor de sementes possivelmente seriam afetados pelo ataque de fungos fitopatogênicos (RAJPUT et al., 2005). 
TABELA 3. Teor de água (TA) de sementes de trigo aos 2,4 e 6 meses de armazenamento.

\begin{tabular}{cccc}
\hline Lote & \multicolumn{3}{c}{ TA $(\%)$} \\
\hline 1 & 2 meses & 4 meses & 6 meses \\
\hline 2 & 12,6 & 12,7 & 12,7 \\
3 & 12,5 & 12,6 & 12,6 \\
4 & 12,7 & 12,7 & 12,7 \\
5 & 11,2 & 11,2 & 11,2 \\
\hline
\end{tabular}

As condições sanitárias iniciais de um lote de sementes são determinantes na manutenção da viabilidade durante o armazenamento. Como foi possível observar as sementes de trigo já continham inoculo de Aspergillus sp. anteriormente ao armazenamento. Durante 0 armazenamento 0 fungo continua 0 seu desenvolvimento mesmo em temperaturas e umidade relativas inferiores às necessárias para a invasão de sementes sadias (DHINGRA, 2005).

\section{CONCLUSÃO}

Foram detectados seis gêneros fúngicos nas sementes de trigo, são eles: Alternaria sp., Bipolaris sp., Fusarium sp., Aspergillus sp.. Penicillium sp. e Rhizopus $\mathrm{sp}$.

Os fungos Alternaria sp., Bipolaris e Fusarium sp., perdem viabilidade durante o armazenamento enquanto Aspergillus sp. e Pencillium sp. apresentam maior percentual de incidência ao longo do período de armazenamento.

\section{REFERÊNCIAS}

BOLIGON A. A.; LÚCIO, A.D.; GARCIA, D.C. Emergência de plântulas de abóbora a partir da avaliação da qualidade das sementes. Ciência Rural, v.40, n.11, p.22742281, 2011.

BRANCÃO, M.F.; del PONTE, E.M.; FARIAS, C.R.J.; BERNARDI, N.L.; ROSSETTO, E.A. Qualidade sanitária de sementes de trigo (Triticum aestivum L.) no Estado Do Rio Grande Do Sul: safras 2004 e 2005. Revista Brasileira Agrociência, v.14, n.2, p.265-271, 2008.

BRASIL. Ministério da Agricultura e Reforma Agrária. Regras para análise de sementes. Brasília, p.365, 2009.

CARVALHO, N. M.; NAKAGAWA, J. Sementes, Ciência, Tecnologia e Produção. FUNEP, Jaboticabal, p.590, 2012.

CONAB. Companhia Nacional de Abastecimento. Acompanhamento da safra brasileira Grãos.

Disponível http://www.conab.gov.br/OlalaCMS/uploads/arquivos/14_06_10_12_12_37_boletim_ graos_junho_2014.pdf. Acesso em 25 de agosto de $201 \overline{5}$. 
DHINGRA, O. D. Teoria da transmissão de patógenos fúngicos por sementes. In: ZAMBOLIM, L. Sementes: qualidade fitossanitária. Viçosa: UFV; DFP. p.75-112. 2005.

EMBRAPA. Empresa Brasileira de Pesquisa Agropecuária. Cultivos - Trigo. Available at: https://www.embrapa.br/trigo/cultivos Acesso em 25 de agosto de 2015.

MACHADO, J.C. Benefícios da sanidade na qualidade de sementes. Informativo Abrates, v.20, n. 3, p.18-19, 2010.

MAPA. Instrução Normativa ํo45 de 17 de setembro de 2013. Disponível em: < http://www.abrasem.com.br/wp-content/uploads/2012/10/Instru\%C3\%A7\%C3\%A3oNormativa-n\%C2\%BA-45-de-17-de-Setembro-de-2013-Padr\%C3\%B5es-deIdentidade-e-Qualiidade-Prod-e-Comerc-de-Sementes-Grandes-CulturasRepublica\%C3\%A7\%C3\%A3o-DOU-20.09.13.pdf>

OHLSON, O. de C.; KRZYZANOWSKI, F. C.; CAIEIRO, J. T., PANOBIANCO, M. Teste de envelhecimento acelerado em sementes de trigo. Revista Brasileira de Sementes, v.32, n.4, p.118-124, 2010.

RAJPUT M.A,; PATHAN M.A,; LODHI A.M,; SHAH G.S,; KHANZADA K.A. Studies on seed-borne fungi of wheat in Sindh Province and their effect on seed germination. Pakistan Journal of Botany, v.37, n.1, p.181-185, 2005.

RUPOLLO, G.; GUTKOSKI, L. C.; MARTINS, I. R.; ELIAS, M. C. Efeito da umidade e do período de armazenamento hermético na contaminação natural por fungos e a produção de micotoxinas em grãos de aveia. Ciência e Agrotecnologia, v. 30, n. 1, p. 118-125, 2006.

TELLES NETO, F.X.B.; REIS, E.M.; CASA, R.T. Viabilidade de Fusarium graminearum em sementes de trigo durante 0 armazenamento. Summa Phytopathologica, v.33, n.4, p.414-415, 2007. 